\title{
Demographic and Epidemiological Transitions in Nepal: Developmental Implications
}

\author{
by Juhee Vajracharya Suwal \\ Dayagani, New Delhi: Adroit Publishers 2012 \\ ISBN: 978-81-87392-94-1 \\ Hardcover, \$36.00, 253 pp.
}

\author{
Reviewed by Alison Yacyshyn \\ Alberta School of Business, University of Alberta
}

Nepal is a country in South Central Asia that is landlocked between China and India and is rich of history and tradition. According to the Population Reference Bureau (2013), Nepal's mid-2013 population was 26.8 million, with approximately 17 per cent of the population residing in urban areas. Nepal is world-famous for Mount Everest, which is at 8,850 $\mathrm{m}$ (the highest point in Asia) and the prayer flags that adorn the streets in Nepal's capital city Kathmandu. In nine chapters, the book Demographic and Epidemiological Transitions in Nepal goes beyond the familiar and provides the reader detailed insight of the country with respect to the country-specific demographics and health conditions.

The first chapter covers the rationale and scope of the research, focusing on how modernization factors, demographic components, and epidemiological changes interrelate in the country of Nepal. This chapter includes brief discussions of significant theoretical traditions, citing Omran (1971), Caldwell (1998), and Olshansky and Ault (1986). A conceptual framework linking modernization and demographic factors to indicators of demographic and epidemiological transition is presented in figure 1.1, which clearly demonstrates how modernization factors tend to be highly correlated. This figure not only provides a justification for discussing these components separately in different chapters of the book, but also serves as an outline of important variables in empirical analysis.

The demographic transition presented in chapter 2 is a foundational theory describing shifts in human populations. The book focuses on the demographic situation in Nepal such as: pre- and post-Second World War situations and fertility transitions. By addressing population and mortality trends, such as life expectancy at birth, child mortality, fertility trends, age-specific fertility rates, and total fertility rates, Nepal's historical situation is clearly outlined.

Chapter 3 focuses on the epidemiologic transition. By outlining the transition stages more broadly, the global epidemiological situation allows the author to place Nepal's epidemiological situation in context. The author notes that the "epidemiological situation in Nepal was not known until fairly recently." Nepal's history is indeed unique, yet it has entered the third stage in the epidemiologic transition. Due in part to the health and development conditions in the country, the discussion is more inclusive than purely economic.

By focusing on birth intervals in Nepal, in chapter 4 the author highlights factors affecting birth intervals, such as women's education, age at marriage, traditional norm and cultural practices, and place of residence. By using the Nepal Fertility, Family Planning and Health Survey (1991), the author could choose appropriate measures and recognize the limitations of the data. The findings allow the author to outline reasons why couples have longer first birth intervals than other intervals. The author notes that women in Nepal seem to have comparatively more control over their reproductive lives. Providing women economic opportunities contributes to reductions of high fertility levels. 
Chapter 5 focuses on socio-cultural practices and women's autonomy among Nepal's ethnic groups and their effects on fertility and family planning. By discussing backgrounds of the following societies: Gurung, Limbu, Rai, Sherpa, Magar, Tamang, Brahmin and Chhetri, untouchable castes, Muslim, Terai, and Newar, the country's diverse cultural existence is outlined. The lifestyles of individuals in these societies are not equal. The ethnic groups exhibit different characteristics and by painting a country with one brush, important details regarding ethnic groups are missed. Although the author suggests that a multivariate analysis of the fertility data for different ethnic groups would be useful to determine the independent role of ethnicity and culture, the book does not necessarily need this additional complexity.

The infant mortality rate has been used to assess the development of Nepal. In chapter 6, the author focuses on determinants of infant mortality in the country. By analyzing the determinants and consequences of infant mortality, several variables are chosen, based on socio-economic and cultural-related factors, healthcare, demographics, and lifestyle. This chapter is more technical than the previous ones, as the author states five research hypotheses and outlines a logistic regression analysis to measure the variables. Of the detailed information presented, the author concludes that the hypothesis stating that infant mortality increases as parity increases is strongly supported. The findings in this chapter provide evidence required for policy planners to implement appropriate programs.

Similar to the previous chapter's organization, chapter 7 focuses on maternal mortality in a well ordered way. By providing background and history of maternal mortality in Nepal, one is warned about data limitations, the causes of maternal deaths, and separating women's health from maternal mortality. In this chapter, six hypotheses are generated and data from the 1996 Nepal Family Health Survey are analyzed with a logistic regression. Although the data consists of a small sample, the author is able to discuss the data in a way that is not statistically complex. Nepal is a nation caught between modernization and tradition. As research on maternal mortality has rarely been done, the results suggest that once maternal mortality has been reduced, the third stage of the demographic_and epidemiological transitions in Nepal will be achieved.

Nepalese are referred to as people on the move, and the author recounts the long historical movement of people in the country in chapter 8, entitled "Regional migration in Nepal: Beyond the push and pull factors." Current internal migration in Nepal, along with the types and patterns of internal migration, allow the reader to see that similar to many countries in the world, the movement of people within and outside Nepal's borders is complex. The three types of migration in Nepal are seasonal, semi-permanent, and permanent, and patterns of migration for different geographic regions are also discussed. The migration data confirm the author's hypothesis that young Nepalese adults will show greater propensity to migrate than those in other age groups. As experienced in other countries, migration of the young age groups impacts the population structure. By outlining the economic, political, health-related and other consequences in terms of migration, the author outlines how important migration is to a country's overall geographic structure.

The conclusion provides a precise summary of the book, focusing on aspects that were covered in detail in the previous chapters. It is clear that factors such as cultural practices of the various ethnic populations of Nepal may affect the demographic transition of the country. It is clear that readers will become aware of the importance of the demographic and epidemiological transitions. The book stays true to its title as the author evaluates Nepal's epidemiological and demographic experiences in all of its chapters in one way or another.

Nepal is the case study in this book, which demonstrates that several modernization factors directly and indirectly link demographic and epidemiologic changes. As with demographic-based research, the author notes that the data used in the book will have changed after publication. A major political change has occurred in the country since the author completed the book, and the new government will have an influence on its population.

Having read this book, it can be stated that the author successfully transports the reader to Nepal without one having to pack their bags! The author is veritably a Sherpa, guiding the reader to and through a country rich with culture and tradition. Given that Nepal is just beginning to enter the third stage of the demographic transition, the country will be faced with complex developmental issues. The author's insight into the country of Nepal is valuable. The end notes included in the chapters show how knowledgeable the author is, as some of the comments are based on the author's own observations and/or experiences. 
Besides being of general interest, to read and learn about Nepal, the book could be used in undergraduate and/or graduate demography courses. Many of the chapters in this book could even be used as standalone chapters for discussion. For example, chapter 4 demonstrates the organized process that goes into answering a research question about which variables one would use when examining birth intervals. The book is a valuable resource and contribution to understanding the demographics of Nepal.

\section{References}

Caldwell , J.C. 1998. The global fertility transition and Nepal. Contributions to Nepalese Studies 25(Special Issue: Fertility Transition in Nepal:1-7.

Olshansky, S.J., and A.B. Ault. 1986. The fourth stage of the epidemiologic transition: The age of delayed degenerative diseases. The Milbank Quarterly 64(3):355-91.

Omran, A.R. 1971. The epidemiologic transition: A theory of the epidemiology of population change. Milbank Memorial Fund Quarterly 49(4):509-38.

Population Reference Bureau. 2013. 2013 World Population Data Sheet. Washington: Population Reference Bureau. 